LA-UR-

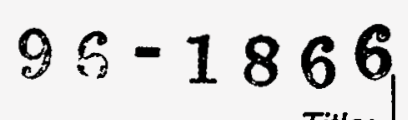

CONF- $960770--3$

Title:

THREE DIMENSIONAL ELASTIC LIDAR WINDS

Fis

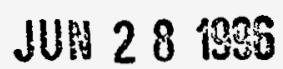

OSTI

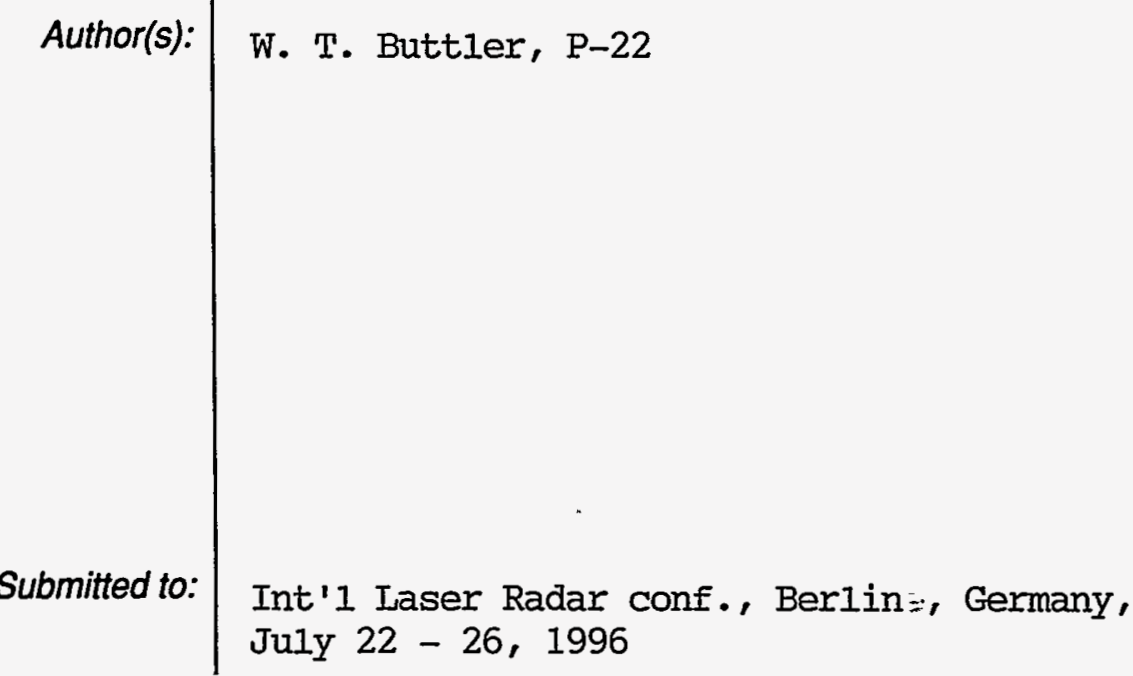

DISCLAMMER

This report was prepared as an account of work sponsored by an agency of the United States Government. Neither the United States Government nor any agency thereof, nor any of their employees, makes any warranty, express or implied, or assumes any legal liability or responsibility for the accuracy, completeness, or usefulness of any information, apparatus, product, or process disclosed, or represents that its use would not infringe privately owned rights. Reference herein to any specific commercial product, process, or service by trade name, trademark, manufacturer, or otherwise does not necessarily constitute or imply its endorsement, recommendation, or favoring by the United States Government or any agency thereof. The views and opinions of authors expressed herein do not necessarily state or reflect those of the United States Government or any agency thereof.
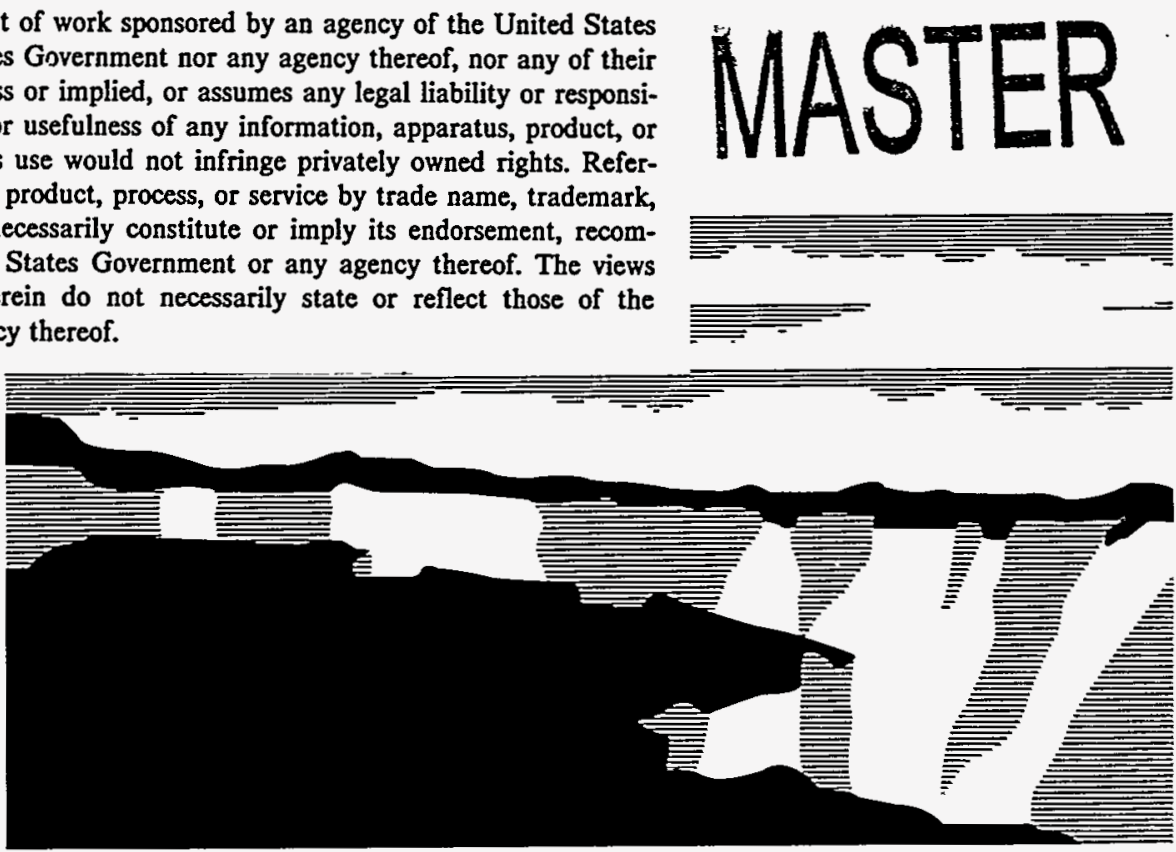

Los Alamos National Laboratory, an affirmative action/equal opportunity employer, is operated by the University of California for the U.S. Department of Energy under contract W-7405-ENG-36. By acceptance of this article, the publisher recognizes that the U.S. Government retains a nonexclusive, royalty-free license to publish or reproduce the published form of this contribution, or to allow others to do so, for U.S. Government purposes. The Los Alamos National Laboratory requests that the publisher identity this article as work performed under the auspices of the U.S. Department of Energy. 


\title{
Three-Dimensional Elastic Lidar Winds
}

\author{
William T. Buttler \\ MS D410, Hydrodynamics and X-Ray Physics, \\ Los Alamos National Laboratory, Los Alamos, New Mexico 87545 \\ E-mail: buttler@wende.lanl.gov
}

\begin{abstract}
Maximum cross-correlation techniques have been used with satellite data to estimate winds and sea surface velocities for several years. Los Alamos National Laboratory (LANL) is currently using a variation of the basic maximum cross-correlation technique, coupled with a deterministic application of a vector median filter, to measure transverse winds as a function of range and altitude from incoherent elastic backscatter lidar data taken throughout large volumes within the atmospheric boundary layer. Hourly representations of three-dimensional wind fields, derived from elastic lidar data taken during an air-quality study performed in a region of complex terrain near Sunland Park, New Mexico, are presented and compared with results from an Environmental Protection Agency (EPA) approved laser doppler velocimeter. The wind fields showed persistent large scale eddies as well as general terrain following winds in the Rio Grande valley.
\end{abstract}

\section{Introduction}

The Border Area Air-Quality Study took place during September 1994, and was implemented to determine wind patterns in Sunland Park, New Mexico, preceding Sunland Park's peak ozone $\left(\mathrm{O}_{3}\right)$ levels. The state of New Mexico believes the majority of $\mathrm{O}_{3}$ measured in Sunland Park is produced in El Paso, Texas, and Juarez, Mexico, and carried with the wind into Sunland Park from those regions. Further, the state of New Mexico may be able to continue economic development in Sunland Park if they can show that winds are from El Paso, Texas, and Juarez, Mexico, prior to peak $\mathrm{O}_{3}$ levels in the Sunland Park, New Mexico, area.

\section{Method}

Wind Fields are reduced from data acquired with the Los Alamos National Laboratory (LANL) mobile lidar system [1]. The system is a monostatic elastic backscatter lidar which emits light of 1.064 micron wavelength. The laser was pulsed at $50 \mathrm{~Hz}$ and 150 $\mathrm{mJ}$ per pulse. The backscattered signal was digitized at a rate of 20 mega-samples per second, and the signal was measured with an infrared enhanced avalanche photo diode with a $3 \mathrm{MHz}$ bandwidth. The lidar system used a 12-bit digitizer.

Lidar wind data files were acquired by rastering the lidar system through three different sets of observation angles for a time period of about $63 \mathrm{~s}$ per file [1], [2]. The elevation angle for each file's three observation angles was fixed and a small angle separated the azimuthal angles; observation angles one and two (and two and three) were separated by $0.45^{\circ}$, and observation angles one and three were separated by $0.9^{\circ}$. This lidar 
scanning pattern (referred to at LANL as a correlation scan) produces an image containing aerosol backscatter information as a function of time and range from the lidar along each observation angle.

Wind information are reduced from each correlation scan with a maximum cross-correlation technique [1], [3]. In this application, maximum cross-correlation works as a pattern recognition scheme. Aerosol patterns imaged by the lidar along one observation angle are cross-correlated with aerosol patterns imaged at the other observation angles to create a wind data base for each correlation scan (data file). Cross-Correlation is accomplished by selecting subimages (or tiles) from one of the observation angle images and slipping the tile through the images at the nearby observation angles. Cross-correlations below $75 \%$ are rejected and the resulting wind data base is postprocessed with a deterministic application of a vector median filter to determine trends in the aerosol transport [1], [4]. In the deterministic application, the vector median filter is applied to unit-vectors, or the direction vectors from the wind data base. This application gives the median direction the aerosols are travelling.

Forty files per hour were acquired during time periods preceding peak $\mathrm{O}_{3}$ levels in Sunland Park on the 8, 9, 10, and 11 of September 1994. These files covered $110^{\circ}$ in the azimuthal dimension and were acquired between $2^{\circ}$ and $22^{\circ}$ in the elevation dimension. This permitted the measurement of three-dimensional winds (horizontal winds as a function of range and altitude) throughout a large volume of the boundary layer each hour.

Data for comparison with a laser doppler velocimeter (LDV) were acquired twice each day. The LDV was provided by the Physical Science Laboratory (PSL) of New Mexico State University at Las Cruces, New Mexico, for experimental integrity.

\subsection{Lidar/LDV Wind Comparisons and Wind Fields}

The PSL LDV measures wind profiles by positioning the laser at a $45^{\circ}$ elevation angle and rotating the system through $360^{\circ}$; doppler data as a function of altitude are acquired as the system rotates. The doppler data are fit to a sine function and the absolute maximum and minimum wind speeds are averaged and divided by the cosine of $45^{\circ}$ to determine the wind speed with height. The wind direction is determined as the direction of maximum doppler shift. The LDV cycled through $360^{\circ}$ every $-5 \mathrm{~s}$ and measurements at $500 \mathrm{~m}$ altitude represent wind averages over horizontal distances of $1,000 \mathrm{~m}$. Each lidar wind measurement represents time averages of 10's of $s$ and distance averages of a few $m$ to 100 's of $m$. The LDV and lidar represent two different remote measurement systems and it is not expected that they will agree at all times. However, good agreement between the systems is expected in steady wind conditions. A sample of the LDV data can be seen in Fig. 1.

Fig. 2 shows a comparison between two LDV vertical profiles and two lidar vertical profiles for 11 September 1994. The lidar data are plotted with error bars [1]. The errors are estimated from the uncertainties in time and position of the lag images with respect to the principal tiles. Uncertainties in the lidar's ability to accurately return to the azimuthal angles are also included. All of the uncertainties are based on the physical limitations of the lidar system. 


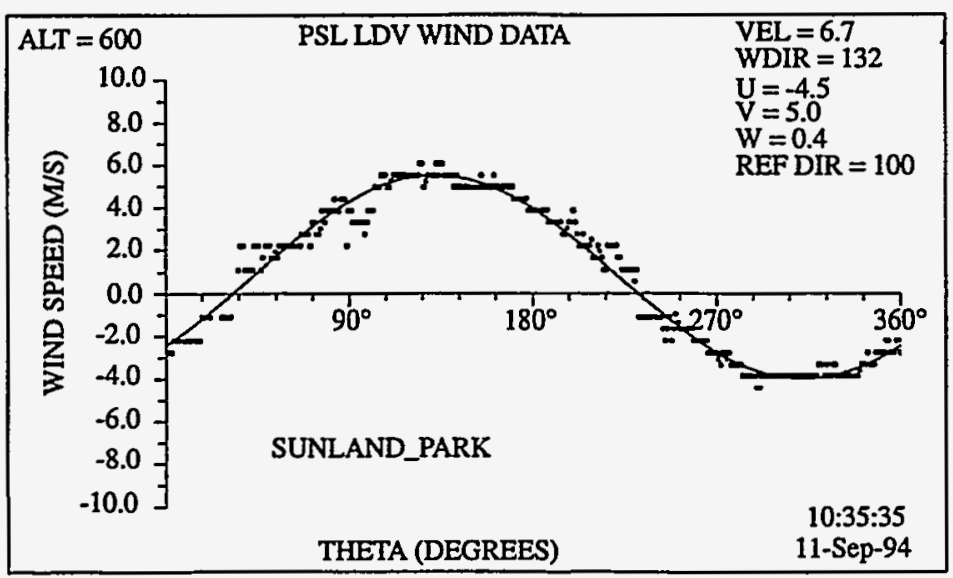

Fig. 1: Laser Doppler Velocimeter Doppler Shift Plot

The wind speed (VEL) in the upper right corner is the absolute average of the minimum and maximum wind speeds divided by $\cos \left(45^{\circ}\right)$; i.e., ws $\approx(5.5+4.0) \times \sqrt{2} / 2 \mathrm{~m} / \mathrm{s}=6.7 \mathrm{~m} / \mathrm{s}$. The wind direction (WDIR) of $132^{\circ}$ in the upper right corner is measured from true north and corresponds to the maximum doppler wind.

(A) 11 SEPTEMBER, 0800-0900 HOURS

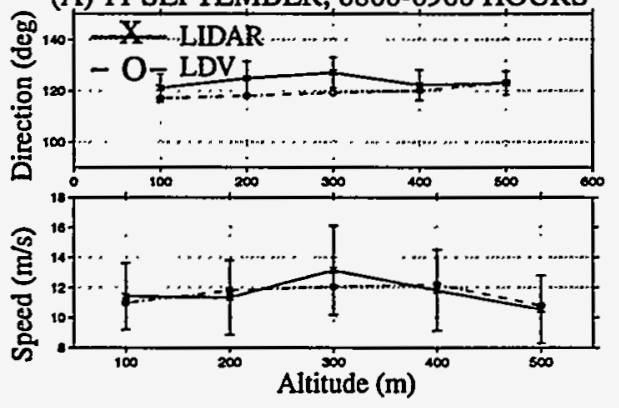

(B) 11 SEPTEMBER, 1500-1600 HOURS

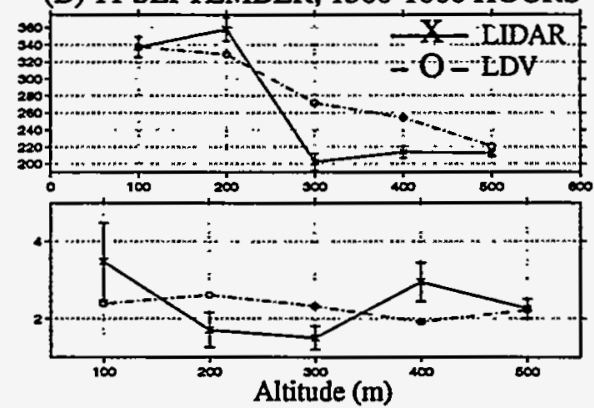

Fig. 2: Lidar/LDV Wind Comparisons for September 11, 1994 (Calibration Runs)

Both these lidar and LDV data were unit-vector median filtered. All data within $\pm 5^{\circ}$ of the median direction were vector averaged and plotted. Dashed lines marked by an ' $o$ ' correspond to LDV data. Solid lines, with error bars and marked by an ' $x$ ', correspond to lidar data. LDV wind speed uncertainties are estimated to be about $\pm 0.25 \mathrm{~m} / \mathrm{s}$.

(A) The left plots are the 0800 to 0900 hours calibration run and show strongly correlated results. The large uncertainties in the wind speeds are related to the high wind speeds (very fast transport times). (B) The right plots are the 1500 to 1600 hours calibration run and show good agreement in wind speed and direction. Of interest is the wind shear seen by both the LDV and lidar system. The LDV data at 300 and $400 \mathrm{~m}$ show wind directions from the lidar's blind spot. This blind spot is a physical limitation of the algorithm, and results when images between the slightly separated azimuthal angles are cross-correlated. This could be one reason Eloranta departed from the three-angle scanning pattern for volume scans [5]. 
Fig. 3 shows an elastic lidar wind field for one hour on 10 September 1994. These trends were typical and support the conclusion that winds flowed from El Paso, Texas, and Juarez, Mexico, in the hours preceding peak $\mathrm{O}_{3}$ levels in the Sunland Park area.

\section{References}

1. Buttler, W. T., "Three-Dimensional Winds: A Maximum Cross-Correlation Application to Elastic Lidar Data," Los Alamos National Laboratory Thesis LA-13121-T (1996).

2. Sroga, J. T., and E. W. Eloranta, "Lidar Measurement of Wind Velocity Profiles in the Boundary Layer," Journal of Applied Meteorology, Vol. 19, No. 5 (1980).

3. Garcia, C. A. E., and I. S. Robinson, "Sea Surface Velocities in Shallow Seas Extracted From Sequential Coastal Zone Color Scanner Satellite Data," Joumal of Geophysical Research, Vol. 94, No. C9 (1989).

4. Simpson, J. J., and J. I. Gobat, "Robust Velocity Estimates, Stream Functions, and Simulated Lagrangian Drifters from Sequential Spacecraft Data," IEEE Transactions on Geoscience and Remote Sensing, Vol. 32, No. 3 (1994).

5. Schols, J. L., and E. W. Eloranta, "Calculation of Area Averaged Vertical Profiles of the Horizontal Wind Velocity From Volume-Imaged Lidar Data," Joumal of Geophysical research, Vol. 97, No. D17 (1992).
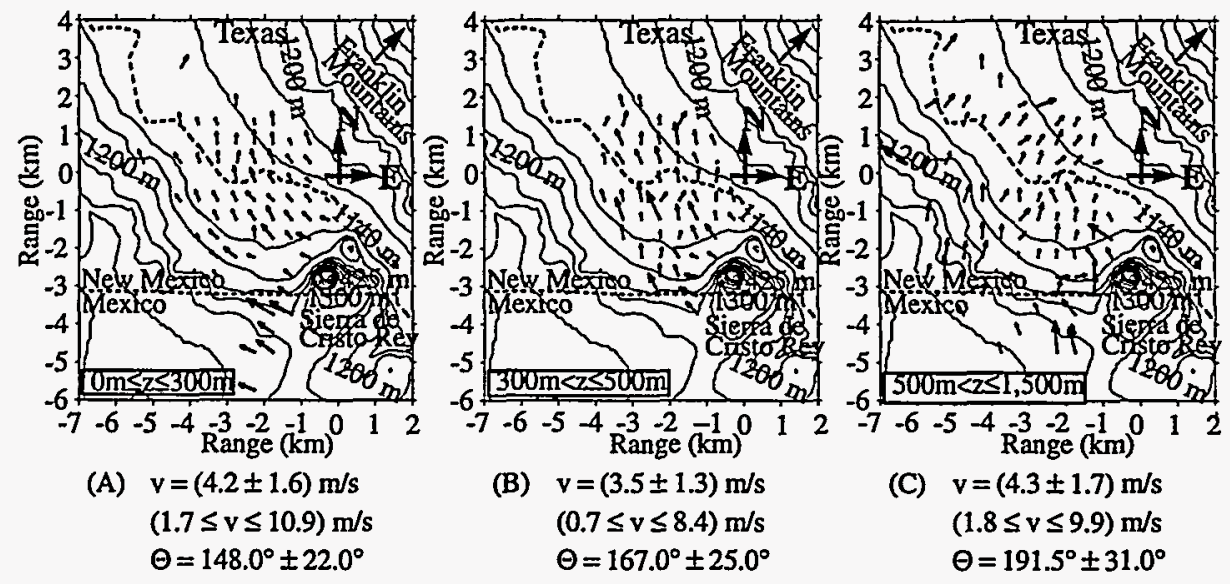

Fig. 3: Lidar Winds From 1200 to 1300 Hours (10 September 1994)t

(A) Lower level winds show low to moderate magnitude with moderate variabilities (the moderate variabilities indicate that thermal turbulence has begun). These winds seem to curl toward the Franklins as the winds travel up the Rio Grande Valley. Near the pass, and south of Sierra de Cristo Rey, the winds continue to be from the SE. (B) Middle level winds are similar to the previous hour's data in magnitude, direction, variabilities, and continue to exhibit terrain induced effects. (C) Upper level winds show a interesting eddy just west of Sierra de Cristo Rey that is likely a short time scale structure. Similar eddies appear in this region at other times, however, suggesting eddies in this area may be common. The rest of the upper level winds show low to moderate winds with moderate variabilities in direction and low variabilities in magnitude. The upper level winds mainly travel from the south and curl toward the Franklins. 